\title{
Streams of words: Hydrological lexicon in Jahai
}

\author{
Niclas Burenhult* \\ Max Planck Institute for Psycholinguistics, Language and Cognition, P.O. Box 310, $6500 \mathrm{AH}$ \\ Nijmegen, Netherlands
}

\begin{abstract}
This article investigates hydrological lexicon in Jahai, a Mon-Khmer language of the Malay Peninsula. Setting out from an analysis of the structural and semantic properties as well as the indigenous vs. borrowed origin of lexicon related to drainage, it teases out a set of distinct lexical systems for reference to and description of hydrological features. These include (1) indigenous nominal labels subcategorised by metaphor, (2) borrowed nominal labels, (3) verbals referring to properties and processes of water, (4) a set of motion verbs, and (5) place names. The lexical systems, functionally diverse and driven by different factors, illustrate that principles and strategies of geographical categorisation can vary systematically and profoundly within a single language.
\end{abstract}

(C) 2006 Elsevier Ltd. All rights reserved.

Keywords: Jahai; Lexical semantics; Loanwords; Metaphor; Motion verbs; Place names

\section{Introduction}

The flow of water holds a special position in the language of the Jahai, a group of hunter-gatherers in the Malay Peninsula. It is semantically encoded in deictic categories, relational nouns and motion verbs, for example, and it features prominently in the lexicon relating to the geophysical environment. This article explores such lexical categorisation of hydrological features in Jahai. It describes the structural and semantic properties as well as the indigenous vs. borrowed origin of hydrological terminology, as well as its lexical relations and the role of metaphor. It also outlines the Jahai system of place-naming, which is

\footnotetext{
* Tel.: +31 243521 270; fax: +31 243521213 .

E-mail address: Niclas.Burenhult@mpi.nl
} 
closely connected to notions of drainage. The Jahai hydrological lexicon provides several interesting windows on principles and strategies of landscape categorisation in language.

\subsection{The language and its speakers}

Jahai is a member of the Northern Aslian subbranch of the Aslian branch of the MonKhmer language family (and ultimately the Austroasiatic stock). It is spoken by about 1000 hunter-gatherers, traders and occasional swidden cultivators in the interior parts of the Peninsular Malaysian states of Perak and Kelantan, as well as in neighboring parts of southern Thailand (see Fig. 1). Jahai speakers form the largest ethnic group of a cluster of hunter-gatherer populations referred to generically in the anthropological literature as the Semang. Their subsistence system is based on hunting, fishing and the collecting of wild tubers and vegetables. Traditionally the Jahai live in mobile bands of 15-50 people, sheltering in windbreak huts and moving camp every one to two weeks. Nowadays most Jahai are settled in permanent villages under regroupment programs established by the Malaysian government (van der Sluys, 1999, pp. 308-310; Burenhult, 2005a, pp. 1-6).

Like other Aslian languages, Jahai has a rich set of vowel phonemes, a complex system of word formation involving intricate and productive processes of derivational affixation and reduplication, as well as rich pronominal and demonstrative systems. The language has long been heavily influenced by Malay, as reflected for example in a large number of loanwords (Burenhult, 2005a). ${ }^{1}$

\subsection{The geographical setting}

Jahai territory covers a landlocked area of about $3500 \mathrm{~km}^{2}$ in the Malaysian states of Perak and Kelantan, and adjacent parts of Thailand's Narathiwat province. Its topography is dominated by the mountains of the Titiwangsa range, the relief ranging between about 100 and $1800 \mathrm{~m}$ above sea level. The area forms a maze of narrow, steep-sided valleys and is drained by swift-flowing mountain streams, which are fed by countless rivulets that trickle down from their sources on the mountainsides. The streams are shallow and generally fordable, and their long profile is characterised by numerous rapids and vertical or near-vertical nick-falls. Only at the eastern and western peripheries of the territory do rivers begin to slow down and become sizable. Drainage occurs in two major directions. The main, western part of the territory is drained by the upper reaches of the Perak River, which flows southwest to the Straits of Malacca. A smaller, eastern part is drained by the Pergau River, which flows southeast towards the Kelantan River, which meets the South China Sea near Kota Bharu.

\footnotetext{
${ }^{1}$ The phonemic inventory of Jahai has 20 consonant phonemes and 16 vowel phonemes, 9 oral vowels contrasting with a slightly smaller set of nasal counterparts. The orthography employed in this paper is phonemically based and largely conforms to the IPA. It departs from the standard IPA and from the orthography used in Burenhult (2005a) in that the voiced palatal stop is symbolised by $j$ and the palatal approximant by $y$. The phonemic rendering of forms requires that epenthetic vowels are omitted, which frequently results in complex consonant clusters. For information on syllabification patterns and the phonetic realisation of epenthetic vowels in Jahai, see Burenhult (2005a, pp. 33-38).
} 


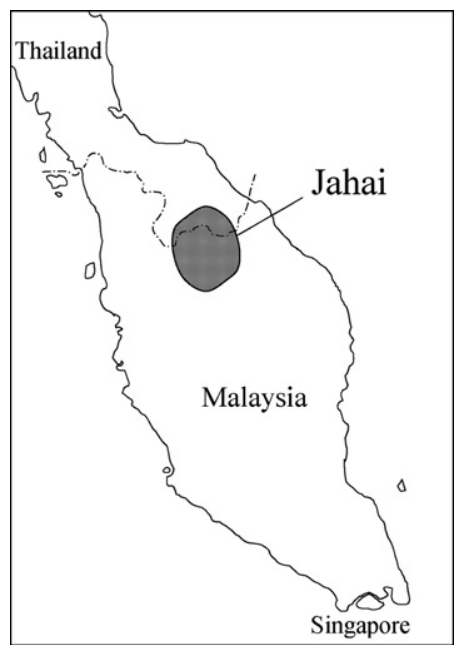

Fig. 1. Map of the Malay Peninsula indicating the approximate distribution of Jahai.

Primary Dipterocarp rainforest characteristic of foothills and lower mountain regions forms a dense cover over most of the mountainous territory. Precipitous outcrops of bare rock sometimes create gaps in the forest cover, and limestone formations of a karst character occur in some places. The territory is flanked to the east and west by two conspicuous geological landmarks which are of great mythological significance to the Jahai: the two peaks of Kenderong and Kerunai (Rlay and Rnaysh in Jahai) near Grik in the west, and the precipitous limestone formation of Batu Melintang or Batu Reng (Rem in Jahai) by the Pergau River near Jeli in the east.

\subsection{The present study}

This study investigates those parts of the Jahai lexicon which denote aspects of the hydrological environment. It is based on data collected during several fieldtrips between 1998 and 2006 to the semi-settled Jahai community of Sungai Banun, a resettlement village in the Hulu Perak district of Perak state, Peninsular Malaysia.

The account is part of a larger study of the role of landscape-related categories in Jahai spatial language and cognition. This is intended to descriptively outline the domain from a linguistic point of view. It thus complements the detailed and more anthropologically oriented accounts of landscape conceptualisation given by e.g. Lye $(1997,2004)$ for the Batek, a linguistically and culturally closely related group of Semang. An earlier report of landscape terms and place names in Jahai is given in Burenhult (2005b), which tentatively outlines the landscape domain in full and introduces some of the categories explored in more detail here.

The analysis draws on different types of data. Conventional elicitation and interviewing, recently enriched by the 'Landscape terms and place names elicitation guide' developed by Bohnemeyer et al. (2004), has served as a basic strategy for collecting and defining terminology. To a large extent this elicitation has been conducted in situ, that is, in the actual landscape setting, for example during travels through Jahai territory by foot or by car. In 
addition, elicitation techniques targeting landscape categorisation have been designed and tested in the field. In particular, so-called photo-matching games were employed to prompt spontaneous discourse between native speakers about landscape categories. These games involved sets of photos of different landforms. One player (the Director) was given a set of photos and was asked to describe the scenes shown in such a way as to enable another player (the Matcher) to identify the correct photo from an identical set. These sessions were recorded on video. Another task involved the colouring in of referents of landscape terms on simple line drawings of landforms. Furthermore, important insights have been gained from the analysis of route descriptions and other landscape-related description captured on video. Informants (altogether 6) were all male native speakers of Jahai aged between 18 and 60 .

The following sections of this paper investigate six formal manifestations of Jahai hydrological lexicon. Section 2 introduces the general nominal category of tom 'water'. Section 3 shows how metaphor from animate domains is employed in compounds to subcategorise tom according to part and size, and how such metaphor forms standardised templates which are generically applicable to drainage. Section 4 describes borrowed hydrological lexicon (mainly from Malay, the neighboring Austronesian majority language) and shows that such lexicon systematically targets salient hydrological features which are not handled by the indigenous metaphors. Section 5 treats hydrologically related categories in the class of verbals, especially a group of semantically specific forms denoting properties and processes of water as well as a set of motion verbs encoding movement in relation to water features. Section 6 outlines the strategies of place-naming, which are closely associated with drainage. Section 7 discusses the marked division of semantic labor between these various lexical manifestations and argues that they reflect distinct principles and needs in landscape categorisation. It also briefly addresses the question of whether or not 'landscape' forms a well-defined and fundamental semantic domain in Jahai.

\section{A fundamental category: tom 'water'}

In the description of Jahai nominal landscape terminology it is convenient to make a distinction on structural grounds between simplex and complex forms. Simplex forms are monolexemic, synchronically unanalysable nominals. These represent a rather small number of general categories, like $t$ m 'water', $t e^{\text {? ' }}$ ground', 'soil', and hip 'forest'. Complex forms are nominal compounds which always consist of a simplex term combined with a metaphorical noun (see Section 3).

We will here be concerned with one such general category, namely tom 'water'. The term tom is generally applicable to units, courses and bodies of water of all kinds and sizes. Thus, for example, no lexical distinction is made between water as a substance and water as a landscape feature, or between different manifestations of running water (cf. size-based English terms like river, creek, stream, rivulet, trickle, tricklet etc.). Indeed, tom can refer to anything from a whole drainage system to any subpart thereof, down to a single drop of water. Context alone disambiguates what is referred to, unless one employs metaphorical compounds (see Section 3). There are no other simplex terms which refer to water features (with the exception of some loans, see Section 4). These points are significant, because they suggest that Jahai places much emphasis on water and its drainage as a unitary and coherent feature in landscape. Further evidence for this is presented in Section 3. 


\section{Complex nouns and metaphor: 'parts' and 'kinds' of water}

Complex terms are nominal compounds consisting of the simplex term tom combined with a metaphorical noun drawn from human or, perhaps more generally, animate domains. There are two such domains: body parts (creating partonymy) and kinship terms (creating size taxonomy).

\subsection{The body metaphor}

In Jahai, the body serves as a productive, systematic and coherent metaphorical template with which the rest of the physical world is mapped, referred to and described. Dwellings, camps, trees, tools, fire and the universe as a whole are talked about in terms of 'bodies' exhibiting features like 'heads', 'eyes', 'noses', 'shoulders', 'bums' and 'feet'. Water is no exception, and it is within hydrological categorisation that the body metaphor takes on some of its most interesting manifestations. ${ }^{2}$

\subsubsection{Formal characteristics}

Compounds involving the body metaphor are left-headed constructions in which the body part term represents the head and $t 5 m$ is the modifier, that is, BODY PART $+t \supset m$. In translations into English, where the order of compound constituents is the opposite one, constructions will be rendered as water + BODY PART, that is, 'water-head' rather than 'head-water'. A complication is that, in Jahai, there is no straightforward way of distinguishing compounds from possessive constructions on syntactic grounds. ${ }^{3}$ However, the high degree of lexicalisation exhibited by the metaphorical constructions suggests that they are better translated into English as compounds rather than possessive constructions. This will be the translational convention consistently employed here. Thus, the literal translation of a metaphorical compound like mit tom 'river source' will be 'water-eye' rather than 'water's eye', 'eye of water' or 'eye-water'.

\subsubsection{A bodily template}

Among metaphorical body part terms there is a focal set of six terms, forming three pairs, which are employed to create spatial opposites. Together, these provide a threedimensional template of axes which forms a basic scaffolding for most metaphorical mapping of body parts onto inanimate entities. These opposite pairs include sagittal kuy-kit 'head'-'bum', vertical kro?-dada' 'back'-'chest', and lateral tem-wĩ '; 'rightside'-'leftside'.

The head-bum dichotomy is used to create opposite extremes on the sagittal axis, typically the beginning and end of an entity. The distinction can be applied on the horizontal plane, but the beginning part is usually associated with higher elevation. Thus, in the case of tom, the opposites on the sagittal axis are represented by kuy tom 'headwaters' (literally 'water-head') and kit tom 'river-mouth' (literally 'water-bum'). The head denotes an extensionally rather vague uppermost, beginning portion of a drainage system; the bum refers to the point where the drainage system in question ends and empties into a larger system.

\footnotetext{
${ }^{2}$ For an account of body part terminology in Jahai, see Burenhult (2006).

${ }^{3}$ Constructions of this type, so-called 'associative phrases', can express a whole range of semantic relations, including possession, physical contiguity or proximity, part/whole, object/purpose and entity/source, among others (cf. Kruspe, 2004, pp. 213-218).
} 
The back-chest contrast is used to distinguish opposite facets on the vertical axis, i.e. uppermost surface and underneath surface. The opposites are here represented by $k r r^{\text {? }}$ tom 'surface of water' (literally 'water-back') and dada' tom 'bottom of river' (literally 'water-chest').

The rightside-leftside distinction contrasts opposing sides of a feature on the lateral axis. These opposites - tem tom, literally 'water-right', and $w \tilde{\imath}$ ' $t o m$, literally 'water-left' - refer to fixed sides of a water-course, where the respective terms refer to the right and left sides as one is facing upstream. Therefore, if one is facing downstream, the 'water-left' will be to one's right and vice versa. Thus, the left or right side of a river will be constant and not change according to one's orientation in relation to the flow of water. ${ }^{4}$

This basic, three-dimensional template of sagittal, vertical and lateral opposites forms a positionally fixed system for the mapping of facets onto drainage systems and other landscape entities (cf. Levinson, 2003, pp. 76-79). In addition, there is a set of supplementary body part metaphors with rather fixed positional characteristics in relation to the basic frame. For example, upper tributaries in a drainage system may be referred to as klapəh tom, literally 'water-shoulders'. Correspondingly, lower tributaries may be referred to as bli' tom, literally 'water-thighs', or can tom, literally 'water-feet'. Also, a set of more detailed features denoted by body part metaphors are located in the water's head: mit tom 'river source', literally 'water-eye', refers to a point where surface run-off first assembles to form a trickle, or where spring water emerges from the ground; moh tom, literally 'waternose', is a point where such trickles join to form a larger rivulet; 'ntey tom, literally 'waterear', refers to a peripheral source in the water's head.

The Jahai lexical treatment of water and its drainage thus reflects an entirely coherent prostrate 'body' with its head at the upper end of the system. The body metaphor subcategorises the general concept of 'water' into a set of interlocked features, creating what may be viewed as a 'part-of' relationship or partonymic hierarchy within it. The positionally fixed character of most of the 'parts' makes the body a systematic and unitary template for the mapping of features onto drainage. Note that the specific parts picked out by the metaphorical labels are constants of any drainage system - source, upper part, end, rightside, leftside, surface, bottom etc. - but that these features are not always physically well-defined or salient. For example, a water-head is positionally fixed, but its boundaries are vague. A water-eye, while representing the extreme and concrete beginning of every drainage system, is hardly perceptible in landscape. Furthermore, from a utilitarian point of view, the features labelled by metaphor do not in themselves necessarily have any particular significance. No Jahai activity is exclusively associated with the actual hydrological features labelled water-eye, water-left or water-head. Thus, the template operates independently of the salience and utilitarian properties of individual hydrological features.

Note also that the template is entirely flexible in relation to the size of the drainage system and may be applied at any level of scale. A sizable river has eyes, a head, a bum, a back and a chest, just like a small trickle has its own eye(s), head, bum etc. This scalar

\footnotetext{
${ }^{4}$ Fixed use of left/right in relation to the banks of rivers also exists in some European languages, e.g. with reference to the banks of the Rhine, Seine and Thames, as well as in standard hydrological terminology. In these systems, however, right/left is mapped in the opposite way, so that the left bank of a river is that which is to the left if one is facing downstream.
} 
flexibility illustrates how the Jahai body template can be characterised as a so-called fractal, a shape which can be subdivided into parts, each of which is a smaller version of the whole (cf. Mandelbrot, 1975, 1982).

In sum, a major capacity of the body template is its generic applicability to any drainage system at any level of scale. It achieves this capacity by only including features which are common to all drainage systems and which are positionally fixed in relation to each other, and by operating independently of the size, natural salience and utilitarian properties of these features. The template is 'underspecifying' in the sense that its components are semantically general and vague enough to accommodate to global and fractal application.

\subsection{The kinship metaphor}

A second lexical domain from which metaphors are drawn for employment in complex landscape terms is kinship. Like the body metaphor, the kinship metaphor is not restricted to drainage but is applied to physical entities in general. In terms of number of metaphorical terms used, the kinship metaphor is less elaborate and productive than the body metaphor. Of the approximately 25 kinship terms recorded for Jahai, only two are regularly employed for metaphorical purposes: $b \dot{\boldsymbol{t}}$ ' 'mother' and $w \ni \eta$ 'child', 'offspring'. Other terms occur but only marginally. Although mapped onto the same entities, the kinship metaphor operates independently of the body metaphor and complementarily handles other distinctions. Instead of creating partonymic relationships on the basis of positional characteristics of features, it expresses taxonomic relationships based on size.

Structurally, complex forms involving a kinship term follow the same basic principle as those with body part terms: a metaphorical noun is combined with tom to form a nominal compound. However, the kinship compounds present structural variation not observed in body compounds. In kinship compounds, the relative order of tom and kinship term can vary in relation to the syntactic identities of the constituents of the left-headed compound construction. The kinship term may fill the head slot, in which case $t$ s $m$ is the modifier, or vice versa. For example, the combination of the child metaphor with $t$ tom can render two complex forms: woy tom 'water-child' and tom woy 'child-water'.

Although the semantic differences between these two constructions are not entirely clear, the data available at present suggest that forms in which the kinship term represents the head are productive, less lexicalised and signal general classification according to size. The use of mother can be seen here as representing a general augmentative strategy, child being the diminutive counterpart. Thus, speakers use an augmentative form like $b \dot{t} ; t$ sm, literally 'water-mother', to indicate that the water feature in question is big. The diminutive counterpart woy tom, literally 'water-child', indicates that the feature is small. The size of these referents is variable and dependent on context.

Constructions in which tom is the head and the kinship term is the modifier are less common, more lexicalised and semantically more specific and fixed. For example, tom $w \ni \eta$, literally 'child-water', refers strictly to trickles of a particular kind and size. These barely visible trickles may only be a couple of decimetres wide, and their course is too narrow to open up natural corridors through the surrounding vegetation which would facilitate human movement and extend the field of vision. They are not necessarily permanent (some only occur during heavy downpours) but they do follow permanent channels in the landscape (so-called carək), typically in steep terrain. The conceptual importance of these 
little trickles is reflected in the fact that the area they drain has close association with Jahai practices of place-naming (see Section 6). The opposed form tom bï'; 'mother-water' refers to the larger watercourse which a child-water feeds into, irrespective of size. Thus, a mother-water is labelled so by virtue of its relation to the child-water. ${ }^{5}$

Also, tom + KINSHIP TERM compounds occasionally involve kinship terms other than mother and child. For example, tom kneh 'wife-water' and tom ksiy 'husband-water' are sometimes described as denoting two branches of a drainage system of roughly the same size. However, such examples are uncommon and their detailed semantic properties are unknown.

\section{Filling the gaps: the role of loanwords}

Approximately one-fifth of the total Jahai vocabulary collected by the author consists of forms borrowed from Malay, the Austronesian majority language of the Malay Peninsula. The loans frequently denote and accompany modern phenomena recently introduced into Jahai society, but they often also represent basic vocabulary. Sometimes such basic borrowed vocabulary co-exists with indigenous synonyms, in which case the indigenous and borrowed terms are in complementary distribution determined by register. For example, the unmarked term for blood in everyday Jahai is darah (from Malay darah 'blood'), but in mythical contexts and story-telling speakers sometimes use the marked indigenous form bhĩ $m$ 'blood'. In many cases, however, basic borrowed vocabulary items do not have such indigenous synonyms. Most examples of this latter situation are to be found within the landscape domain.

Of the 34 simplex nominal landscape labels documented so far in Jahai, at least 15 are loanwords. Examples include batu' 'rock' (from Malay batu 'rock'), carok 'channel' (from Malay caruk 'runnel', 'ditch'), gahuy 'crevice' (from Malay gaung 'ravine'), and tbiy 'mountain-side', 'slope' (from Malay tebing 'bank'). In fact, with one or two possible exceptions, none of the borrowed landscape terms has an indigenous synonym. This lack of indigenous terminology is surprising given the perceptual salience and common occurrence of many of these features. Terminology associated with water and its drainage offers interesting clues as to the reason for the dependence on borrowed landscape terms.

Several landscape entities associated with watercourses have borrowed labels, mostly of Malay origin. For example, the word for river-bend or meander, kunah, is a borrowed Malay term, kuna 'bend', which in turn is a borrowing of English corner (cf. Lye, 2004, p. 204). A tributary is called cabay (from Malay cabang 'branch', 'bifurcation'). A tongue of land in a watercourse is referred to as pulsw, from Malay pulau 'island'. The word for rapid is jrem, cf. Malay jeram 'rapid'; 'omak 'gush' is from Malay ombak 'wave'. Waterfalls are referred to as lata', cf. dialectal Malay lata 'waterfall', and pools of water (e.g. the

\footnotetext{
${ }^{5}$ Reciprocal child-parent relationship is evident also in Batek (Northern Aslian, Malaysia) conceptualisation of drainage systems (Lye, 2004, p. 57), and the child-mother metaphor expresses size relations in several other Aslian languages (Nicole Kruspe, personal communication), as well as neighboring Malay. It is widespread also in the rest of Mainland Southeast Asia (Matisoff, 1991). A pattern of close association between hydrological terminology and the kinship system at large is described by Wazir-Jahan (1980, pp. 123-124) for Mah Meri (or Ma’ Betisek), a Southern Aslian language of Malaysia.
} 
plunge pool beneath a waterfall) are called lobo?, from Malay lobok 'deep pool'. ${ }^{6}$ No indigenous labels have been identified for these entities. Also, apart from the metaphorical terminology associated with water, outlined in Section 3, indigenous water-related labels without borrowed synonyms are practically non-existent.

The water entities denoted by loans, although common, salient and typical in the local environment, are neither necessary nor omnipresent features of a drainage system. Also, if they occur, their location within a drainage system is not predictable. For example, a waterfall can be located anywhere along the course of a river - as can bends, pools and rapids - and at any level of scale. So, in relation to the category of $t$ ' 'water', such features are impossible to fit into the indigenous metaphorical systems. Or, more specifically, the indigenous categorial system, geared to providing a generically applicable template by subcategorising a general category (water) according to relative location of its features (the body metaphor) and size of its features (the kinship metaphor), cannot handle features whose location, magnitude and presence in general are inconstant. This may help to explain the lack of indigenous labels for these features. Thus, the advantages of underspecification for general applicability come at a cost.

Note that the features labelled with loans are not only salient, common and typical in the local environment, but also frequently of great cultural and utilitarian importance. Waterfalls, for example, are focal points in landscape and have great mythical and magic significance. They also impact everyday activities in that they impede human movement along watercourses. Similarly, pools are central to activities like washing, bathing and fishing, but are avoided during movement involving wading. Tongues of land created by river bends are favorite campsites.

What the borrowing patterns seem to suggest, then, is that foreign vocabulary is imported to label features which are perceptually and/or culturally salient but conceptually suppressed by the pre-existing indigenous system of categorisation. In effect, loans fill gaps created by the indigenous metaphorical template. Viewed in this way, many vocabulary items assumed to be 'basic' appear less so. One has to ask whether Jahai ever had indigenous nouns denoting waterfall, bend, pool and so on. If not, could such gaps in the nominal labelling of salient landscape phenomena be compensated for in other parts of the grammar? This is an issue which will be addressed in Section 5.

The borrowed hydrological terms reinforce the picture of indigenous landscape categorisation outlined in Section 3. They illustrate that the metaphorical templates, designed for global and fractal application to drainage, are so rigid in their avoidance of inconstant features that an entirely different strategy is needed for labelling such features. Incidentally, in return, the metaphorical templates provide clues as to possible factors contributing to the extensive lexical borrowing from Malay into Jahai.

\footnotetext{
${ }^{6}$ The origins of two of these forms remain problematic. Gérard Diffloth (personal communication) suggests that the Jahai form jrem 'rapid' is borrowed from an Austronesian source, but possibly not Malay itself. Also, Diffloth points out that lata' 'waterfall' is ultimately Austroasiatic (not Malay/Austronesian) in origin, going back to a reconstructed Proto-Austroasiatic form *lonta:? 'expanse of rock', and that the dialectal Malay form lata (which is typically found only in place names) may have been borrowed from Aslian. However, the Northern Aslian reflex expected in Jahai would be *lati?, suggesting that lata? is indeed borrowed secondarily from Malay, or possibly from a neighboring Central Aslian language like Temiar, which has a historically expected form lata:? 'gorge', 'waterfall'. So whichever their source, both jrem and lata' can be conclusively identified as loans.
} 


\section{Verbals}

So far our discussion of Jahai hydrological categorisation has been concerned with the nominal labelling of features. However, Jahai exhibits drainage-related categorisation also in the class of verbs. Two manifestations of this will be addressed here: semantically specific verbs and onomatopoeic forms describing the properties and processes of water (Section 5.1) and a class of motion verbs which encode water features (Section 5.2).

\subsection{Properties and processes of water}

Previous sections have outlined an indigenous system of nominal labelling of drainage which reflects a major, general category subdivided by metaphor. This nominal system ignores hydrological features which are not mappable by such metaphor, a niche instead largely reserved for loanwords. Beyond nouns, however, Jahai exhibits a set of verbs and onomatopoeic forms which describe the properties and processes of water features in greater detail. Some 25 such forms have been recorded (listed in Table 1), but these likely represent only a small part of such vocabulary.

\subsubsection{Structural characteristics}

Nouns and verbs form structurally and semantically well-defined and distinct word classes in Jahai. Verbs and onomatopoeia, however, are two closely related classes in Jahai, so much that they are difficult to tease apart on structural grounds. Morphosyntactically, onomatopoeic forms regularly behave like verbs in that they can take subject agreement, be negated, and are available to many of the derivational morphological processes associated with verbs, mainly aspectual and Aktionsart distinctions like imperfective and distributive (Burenhult, 2005a, pp. 113-115). They differ from verbs in that they frequently serve as syntactically optional adjuncts. For the sake of simplicity, the two are dealt with here as 'verbals'.

The water-related verbal lexemes identified here are generally simplex. That is, they are represented by synchronically unanalysable forms, either in the form of roots or fossilised, diachronically complex derivations. In some cases, however, forms have synchronically identifiable components and are then considered complex. A handful of the forms identified here show examples of a type of reduplicative process which has not previously been noted in Jahai. This involves the copying and prefixing of the first and last consonant of so-called sesquisyllabic (or one-and-a-half syllable) forms, e.g. the form $b n$-bson 'to gush downward', derived from a root bson with the same meaning. Normally Jahai processes of consonant copying only target the last CVC syllable (Burenhult, 2005a, pp. 46-58). It is not clear whether this is a fully productive and analysable pattern, but it is interesting to note that it seems restricted to landscape-related verbs. ${ }^{7}$

\subsubsection{Semantic characteristics}

Most forms have meanings related to the sounds and movements of water. A couple of forms denote general aspects of the flowing behavior of water, like $b^{\text {? } \varepsilon k}$ 'to flood', 'to

\footnotetext{
${ }^{7}$ Structurally equivalent processes are found in the class of expressives in Semai (Diffloth, 1976, p. 252; Hendricks, 2001) and Temiar (Benjamin, 1976, p. 178), two Aslian relatives of Jahai.
} 
Table 1

Verbal forms which describe the properties and processes of hydrological features

\begin{tabular}{|c|c|c|}
\hline $\begin{array}{l}\text { Jahai } \\
\text { term }\end{array}$ & $\begin{array}{l}\text { Approximate } \\
\text { translation }\end{array}$ & Other information \\
\hline$b^{?} \varepsilon k$ & 'to flood' & The process of flooding, following heavy rain, hic 'to rain' \\
\hline wit & 'to flow' & $\begin{array}{l}\text { In relation to watercourses, their property of leading in a certain } \\
\text { direction or to a certain location, either upstream or downstream }\end{array}$ \\
\hline mykuy & 'to run up' & $\begin{array}{l}\text { A watercourse's property of leading up to its source or } k u y \text { 'head'; form } \\
\text { derived from } k u y \text { and segmentable as } m y-k u y \text { (with a copied final coda), } \\
\text { but the prefixed morpheme is opaque }\end{array}$ \\
\hline mtkit & 'to run down' & $\begin{array}{l}\text { A watercourse's property of leading down to its mouth or kit 'bum'; form } \\
\text { derived from kit and segmentable as mt-kit (with a copied final coda), but } \\
\text { the prefixed morpheme is opaque }\end{array}$ \\
\hline pgis & 'to fall' & $\begin{array}{l}\text { Of descending water; possibly a causative derivation of } g l s \text { 'to climb } \\
\text { down' }\end{array}$ \\
\hline klihd̃̃h & 'to meander' & $\begin{array}{l}\text { Of a watercourse; form contains traces of morphological complexity (an } \\
\text { iterative } l \text { and a distributive } i \text { and an associated copy of the final } h \text { ) but is } \\
\text { synchronically unanalysable }\end{array}$ \\
\hline jriwẽ $\eta$ & 'to fork' & $\begin{array}{l}\text { The process of two watercourses joining or separating; the form is } \\
\text { opaque but it is tempting to analyse it as derived from the noun } j w \tilde{\varepsilon} \eta \\
\text { 'scorpion' by means of the causative infix }\langle r i\rangle \text {, with the resulting literal } \\
\text { meaning 'to cause a scorpion' (i.e. to be scorpion-shaped) }\end{array}$ \\
\hline wswas & 'to fork' & $\begin{array}{l}\text { The process of two watercourses joining or separating; derived from the } \\
\text { noun was 'fork', 'branch' }\end{array}$ \\
\hline kliscĩs & 'to plunge' & Of waterfall plunging into its plunge pool \\
\hline chìr & 'to splash into pool' & Of waterfall splashing as it reaches its plunge pool \\
\hline chok & 'to roar', 'to brawl' & Of waterfalls and rapids \\
\hline $\operatorname{cch} \tilde{\varepsilon} c$ & $\begin{array}{l}\text { 'to make a splashing } \\
\text { sound' }\end{array}$ & $\begin{array}{l}\text { Of water falling into a pool; form contains traces of morphological } \\
\text { complexity (a copy of the final } c \text { ) but is synchronically unanalysable }\end{array}$ \\
\hline bsวn & 'to gush downward' & $\begin{array}{l}\text { Of cascading water; occurs also in a derived form involving an unusual } \\
\text { form of copying of the first and last consonant: } b n-b s \jmath n\end{array}$ \\
\hline$b s \tilde{s} c$ & 'to gush upward' & $\begin{array}{l}\text { Of cascading water; occurs also in a derived form involving an unusual } \\
\text { form of copying of the first and last consonant: } b c-b s \tilde{c} c\end{array}$ \\
\hline bale? & 'to form ripples' & $\begin{array}{l}\text { Of water forming little waves; Malay loan (?): balik, with various } \\
\text { meanings relating to turning }\end{array}$ \\
\hline supkxc & 'to lap' & Of water against a rock \\
\hline sima? & 'to whirl' & Of water around a rock; Malay loan (?) simbah 'to splash' \\
\hline guley & 'to whirl' & Of running water \\
\hline sna? & 'to stop running' & Of stagnant water; Malay loan: senak 'congestion' \\
\hline knldī & 'to run along water' & $\begin{array}{l}\text { Of various riparian features positioned lengthwise in relation to the flow } \\
\text { of water, e.g. rock faces, mountain sides, sandbanks and fallen tree } \\
\text { trunks }\end{array}$ \\
\hline hajil & $\begin{array}{l}\text { 'to run crosswise from } \\
\text { water' }\end{array}$ & $\begin{array}{l}\text { Of various riparian features positioned transversally in relation to the } \\
\text { flow of water, e.g. rock faces, mountain sides, sandbanks and fallen tree } \\
\text { trunks }\end{array}$ \\
\hline pjol & $\begin{array}{l}\text { 'to stick up above } \\
\text { water' }\end{array}$ & $\begin{array}{l}\text { Of bare rock in a watercourse; occurs also in a derived form involving an } \\
\text { unusual form of copying of the first and last consonant and a distributive } \\
i \text { : pil-pjol }\end{array}$ \\
\hline pjõn & $\begin{array}{l}\text { 'to stick up above } \\
\text { water' }\end{array}$ & $\begin{array}{l}\text { Of grass-covered tongue of land in a watercourse; occurs also in a derived } \\
\text { form involving an unusual form of copying of the first and last consonant } \\
\text { and a distributive } i \text { : pin-pjõn }\end{array}$ \\
\hline sirwur & $\begin{array}{l}\text { 'to stick out from river } \\
\text { bank' }\end{array}$ & $\begin{array}{l}\text { Of bare rock; form contains traces of morphological complexity (a } \\
\text { distributive } i \text { and an associated copy of the final } r \text { ) but is synchronically } \\
\text { unanalysable }\end{array}$ \\
\hline
\end{tabular}


Table 1 (continued)

\begin{tabular}{lll}
\hline $\begin{array}{l}\text { Jahai } \\
\text { term }\end{array}$ & $\begin{array}{l}\text { Approximate } \\
\text { translation }\end{array}$ & Other information \\
\hline $\begin{array}{l}\text { ktir } \\
\text { jatoh }\end{array}$ & $\begin{array}{l}\text { 'to dam up' } \\
\text { 'to be separated from } \\
\text { river bank' }\end{array}$ & $\begin{array}{l}\text { Of rocks forming a natural dam in a watercourse } \\
\text { Of island or bar separated from the river bank by a small divergent } \\
\text { section of the watercourse; Malay loan (?): jatuh 'to fall off' }\end{array}$ \\
\hline
\end{tabular}

drain', wit 'to flow' and mykuy 'to run up' (in the sense of a river leading up to its source, derived from kuy 'head'). Others denote water-flow in terms of its shape, e.g. klihd $h$ 'to meander' and jriwẽy 'to fork'. However, most forms denote the movements and sounds of water in waterfalls and rapids. Examples include kliscĩs 'to plunge' (of waterfall), chir 'to splash into pool' (of waterfall), chok 'to roar', 'to brawl' (of waterfalls and rapids), bson 'to gush downward' and bsic 'to gush upward'.

Another group of verbals denote properties of features located in or along a watercourse. The two most general verbals signal the lengthwise vs. crosswise position of features in relation to the flow of water. Thus, rock faces, mountain sides and fallen tree trunks can klidĩy 'run along water' or hajłl 'run crosswise from water'. These verbals are associated with the notions of sagittality and laterality so evident in the metaphorical strategies of nominal labelling (see Section 3.1). Semantically more specialised verbals include pjol 'to stick up above water' (of bare rock), sirwur 'to stick out from river bank' (of bare rock) and ktir 'to dam up' (of rocks blocking a stream).

Many of these verbals are very specific in encoding particular hydrological features. Such features do not typically have parallel indigenous nominal labels, but sometimes borrowed ones (cf. Section 4). Indigenous nominal reference to these features can only be achieved by creating location nominalisations of the verbals in question, e.g. knldĩ 'place of running along water', from klidĩ 'to run along water' (cf. above), or chrhir 'place of splashing', from chitr 'to splash into pool' (of waterfall). Verbal distinctions therefore handle water features which are very different from those handled by indigenous nouns. They are preoccupied with properties and processes of features which were concluded in Section 4 to be ignored by the indigenous nominal system of labelling (e.g. waterfalls and rapids). Also, unlike the nominal categories, they always handle features which are perceptually available and well-defined (cf. also the borrowed vocabulary in Section 4). There is no formal evidence in this verbal lexicon for higher-order organisation or lexical hierarchy of any sort.

So whereas the indigenous nominal lexicon is primarily geared to expressing generically applicable categories at the expense of detail, verbals do the opposite: they pay close attention to fine perceptual detail but do not subsume under higher-order verbal categories. The categorial organisation of Jahai hydrological terminology therefore provides interesting indications that different levels of representation may associate with separate parts of the grammar.

\subsection{Motion verbs}

The other major manifestation of landscape in the class of verbs is a set of motion verbs which have close association with various landforms. Some 50 motion verbs have been documented in Jahai, about one-fourth of which belong to this landscape class. What 
makes them special is that they denote movement in relation to particular landscape features, and such features generally correspond to those which have nominal labels. With only one exception, these verbs are represented by unanalysable lexemes having no formal connections to their corresponding landscape noun, e.g. through derivation.

The landscape-encoding motion verbs can be broadly divided into two subclasses according to which landscape features they are associated with. One subclass is connected to movement on various features of raised landmass. The other subclass, which is the one which is relevant to the discussion here, is associated with movement in relation to water. These two subclasses are cross-cut by further categorisations according to whether the movement is lengthwise or crosswise in relation to the landscape feature, or whether it involves a circumambulating movement to avoid an impeding feature. All of these verbs prototypically denote motion on foot but may be extended to other means of travelling if applicable, e.g. by car. However, they cannot be extended to denote motion other than that in relation to the particular landscape features.

These verbs are typologically unusual in that they form a well-contained set of distinctions which systematically conflate the semantic components of Motion, Path and Ground. Talmy (2000, pp. 60-62) notes a lack of Ground-encoding systems of motion verbs and ascribes this to lexical economy: any such system would require an enormous verbal lexicon, considering the multitude of potential Grounds to be encoded. Jahai (like other Aslian languages) is no stranger to fine-grained semantic distinctions in verbs, as shown by the landscape-encoding motion verbs. But its Ground-incorporating subsystem of motion verbs does indeed restrict itself to Grounds which are large-scale, constant and omnipresent. Thus, if we look for unusual lexicalisation patterns in motion verbs cross-linguistically, landscape is a promising area in which to start.

\subsubsection{Motion in relation to water}

Lengthwise and typically horizontal motion along a major watercourse (a tom $b \dot{\boldsymbol{t}}$ ? 'mother-water') is called rkruk 'to move along water'. It denotes both wading and dryshod motion along the banks of the watercourse. Such travelling usually involves frequent crossing of the watercourse as well as longer or shorter stretches of lengthwise walking in the water, following the path of least resistance. It can refer to both upstream and downstream motion. A separate verb cik 'to wade across', 'to ford', denotes specifically crosswise wading. The verb piris 'to cross water' is used to denote any crossing of water, by wading or dry-shod (on a fallen tree-trunk or a bridge, for example). It also denotes motion across the flow of water as one moves along the crest of a drainage divide; that is, in places where one moves past sources of trickles and where water flows sideways in two different directions (typically in a lget 'gap', 'pass'). Even if such motion does not intersect actual water-flow, the semantic connection is clear: the direction of movement is transversal to the direction of the flow of water. ${ }^{8}$

Special verbs denote the more inclined motion required along the trickles referred to as tom woy 'child-waters' or the small carok 'channels' periodically containing such trickles (see Section 3.2), which typically lead up steeply to a water-eye at a lget 'gap', 'pass'. Thus, $d \varepsilon y$ denotes upward motion towards a lget along such a trickle or channel; hã $c$ denotes the

\footnotetext{
${ }^{8}$ Note that piris is only used in relation to water. The crossing of other features, like a road or a log, would be expressed with a different verb, lintes 'to cross' (from Malay lintas 'to cross', 'to pass'), which is not used to refer to the crossing of water.
} 
opposite downward motion along the same features. Travelling between two adjacent river valleys typically involves these two types of motion, as the bottom of a lget 'gap', 'pass', usually provides the easiest point of crossing a divide.

The remaining verbs include jlitl 'to move down to water', which denotes downward motion towards a river-bank or into the water itself; the opposite janka? 'to move up from water', denoting upward motion away from the river or its bank; and liwor, which denotes the (avoiding) motion around obstacles along a watercourse. Typical cases are nick-falls and piled up rocks or tree-trunks in a river, which require temporary circumambulating motion away from the watercourse.

The motion verbs show evidence of connections to three of the nominal strategies of labelling. As noted, rkruk, $d \varepsilon y$ and $h \tilde{a} c$ denote movement specifically in relation to features which are labelled with the mother-child metaphor (see also Section 6). All except one (liwor 'to move around obstacle on a watercourse', see below) can be classified as denoting either sagittal (lengthwise) or lateral (crosswise) movement along the axes provided by the body metaphor. The verb liwor, finally, denotes circumambulating movement which in the most typical case avoids a feature labelled with a loan, lata' 'waterfall'.

\subsubsection{Nominalisations}

All these motion verbs, like most Jahai verbs, can be nominalised according to a regular and productive process of morphological derivation. This strategy of derivation creates location nominalisations which in their most general interpretation refer to the concrete feature where the motion takes place. Usually, however, the nominalisations have a more specific purpose of referring to sections of trails or roads which require the type of movement denoted by the verbal base form. For example, $p\langle n\rangle$ iris (from piris 'to cross water') denotes a trail section which runs across water (e.g. a bridge or ford), and $n c-h \tilde{c} c$ (from $h \tilde{c} c$ 'to descend along a child-water') is a downhill trail section which follows a trickle from its source towards the main watercourse.

\section{Drainage and place-naming}

Jahai place names follow a consistent and straightforward referential pattern. Naming conventions are intimately and (as far as can be determined) exclusively connected to hydrology. If we begin at micro-level, each tom woy 'child-water' (see Section 3.2) is associated with a specific place name. Permanence of water-flow is crucial here - channels which only occasionally contain water are not associated with a place name. Importantly, however, the place name does not refer to the watercourse as such, but to a wider surrounding area which typically corresponds to the catchment area of the particular childwater. Such areas are usually only 100-200 m wide but may extend several hundred meters or more uphill along the child-water.

The micro-level named areas associated with the child-waters form dense strings along the main watercourse into which the child-waters feed, the tom bit' 'mother-water'. The catchment areas of such larger watercourses are associated with a macro-level place name. The size of these larger catchment areas varies significantly, but they are typically several kilometers long or more, and they vary in width from a few hundred meters to a kilometer or more. There is not much evidence for further hierarchy in named catchment areas, the relationship between micro- and macro-levels of place names being parallel to that between child-waters (referring to trickles of a particular kind and size) and mother-waters 


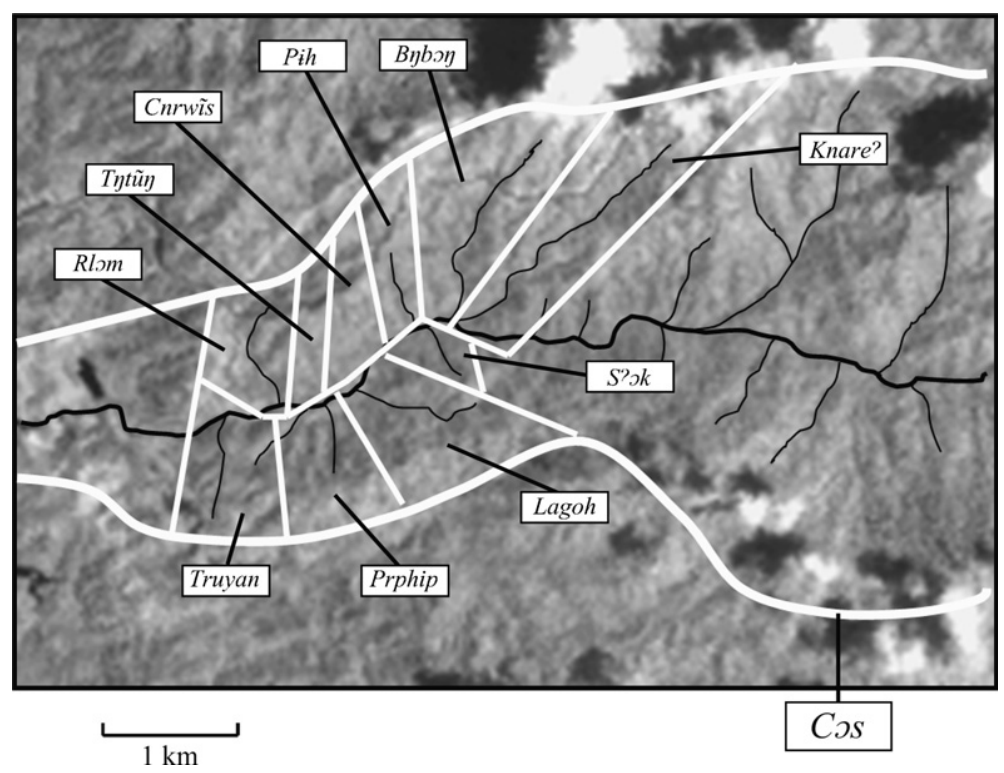

Fig. 2. Satellite image with Jahai place names indicated along a section of the catchment of the Banun River, in Temenggor, Perak, Peninsular Malaysia. The macro-level Jahai place name Cos refers to the main catchment, and micro-level place names associate with the catchments of little tributary trickles of the main watercourse. Source: Landsat.org, Center for Global Change and Earth Observations, Michigan State University (http://landsat.org).

(which vary in size). Note also the parallel to some of the motion verbs discussed in Section 5.2.1. An example of the place name pattern is given in Fig. 2.

There is no Jahai word for catchment area, and the referential mismatch between place names and landscape labels is noteworthy. Since labelled landscape features like watercourses, waterfalls, mountains etc. do not have co-referential place names, individual reference to such features is achieved by means of associative constructions involving a place name and an associated landscape feature, e.g. X's waterfall and Y's mountain. ${ }^{9}$ In effect, two referentially distinct systems of mapping are productively combined in such associative constructions to create exact reference in landscape.

Almost all place names are simplex (monomorphemic) or at least synchronically unanalysable. All are traced to mythological events and may denote species of plants

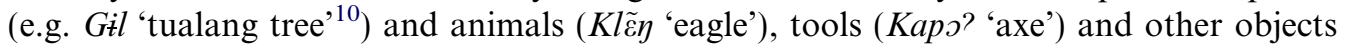

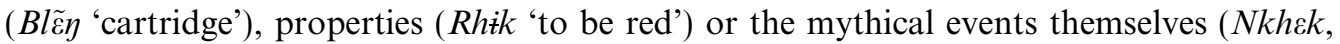
analysable as a nominalisation of the verb $h \varepsilon k$ 'to choke on something'). Many place names are semantically opaque, in which case they are frequently associated with folk etymologies based on phonological similarity (e.g. Cadak, explained as a distortion of carwak, a type of edible plant). Place names never denote or include landscape features, unless they include labels of such features in the productive associative constructions mentioned above.

\footnotetext{
${ }^{9}$ The same applies to traditional sites of habitation (always more or less temporary camps), which are referred to by means of the same type of associative constructions including the names of areas.

10 Koompassia excelsa.
} 


\section{Discussion}

Taking the structural and indigenous vs. borrowed identity of vocabulary as its starting point, this analysis of Jahai hydrological terminology has revealed a marked division of labor between linguistic categories in terms of which features they associate with, denote, and describe. Within the class of common nominals, the indigenous lexicon labels general features and maps them with global metaphor, while borrowed lexicon associates with detail in the form of salient, well-defined but inconstant features. Place names, although intimately connected with drainage, systematically name a type of feature which does not have a corresponding common nominal label. Within the class of verbals, semantically specific terms describe in great perceptual detail the properties and processes of features which are typically not labelled nominally. A subclass of verbs encode movement in relation to running water, forming a template of motion which cross-cuts the nominal strategies of labelling.

While converging and drawing on the same phenomenon in landscape - running water - these various categorial 'systems' are driven by different factors and operate at different levels. Natural and cultural salience can account for the patterns of categorisation in verbals denoting properties and processes, as well as in borrowed nominals. Global 'mapping' and understanding of landscape is the overriding purpose of indigenous metaphor. Unique reference in landscape is the preoccupation of place names. Conditions of human interaction with landscape is what drives categorisation in motion verbs. Moreover, metaphor is in a sense an abstract system applied 'top-down' onto landscape, operating with minimal dependency on individual natural features and their use. In sharp contrast, verbals and borrowed nominals can be thought of as more direct 'bottom-up' products of the natural features themselves.

However, it is when these distinct systems are combined with each other that the purpose and ingenuity of their division of labor becomes apparent. Thus, for example, indigenous metaphor forms an ever-present and plain backdrop to the systems devoted to features, places and motion in landscape. By superimposing the systems onto each other, Jahai speakers are in control of a powerful and flexible apparatus of reference for discourse about all the phenomena that exist and take place in the Jahai world. The most evident exponent of this is perhaps the associative constructions in which place names are combined with nominal labels for exact and unique reference in landscape (see Section 6). ${ }^{11}$

\footnotetext{
11 An anonymous reviewer suggests that the categorial organisation of the hydrological lexicon described here may not be peculiar to Jahai but in fact represents a state of typological 'normality', perhaps especially in the Mon-Khmer and areal context, and that this needs to be properly acknowledged. While such a state of normality may well be the case, it must be pointed out that we know little about how other languages in the region organise this semantic domain. Available dictionaries may provide interesting clues to some of the questions addressed here, but any thorough semantic analysis is likely to require domain-specific first-hand data. To my knowledge, comparable data is not available at present for other Mon-Khmer languages and I would be hesitant to generalise before it is. Having said that, I would like to point out that there are indications that closely related languages may indeed display vastly different types of categorisation in this domain. For example, from my limited experience of Batek De' (southern Kelantan, Peninsular Malaysia), a Northern Aslian relative of Jahai spoken in a similar ecology by a culturally closely related group of people, I can report that the metaphorical mapping of body parts onto drainage is less pervasive than in Jahai and appears to follow fundamentally different principles (see also Lye, 1997, 2004).
} 
But the analysis also highlights a different and more general question. While the verbals and borrowed nominals are firmly anchored in landscape (in the sense that they do not denote or describe phenomena beyond it), the metaphorical templates are not. They are certainly also applied to landscape features other than drainage, like forest and raised landmass, but they do not restrict themselves to this. Any physical entity is available to such metaphorical mapping, so that a drainage system cannot be said to behave differently from a house, a car, a pen, or fire. In this respect, it is difficult in the case of Jahai to see 'drainage' or even 'landscape' as a basic domain or backdrop against which other human experience takes place. Indeed, it is the metaphorical templates themselves, or rather their source domains of body and kinship, which form the most fundamental dimensions along which the Jahai categorise the physical world.

\section{Acknowledgements}

I wish to express my acknowledgements to the Economic Planning Unit, Putrajaya; the Department of Aboriginal Affairs, Kuala Lumpur; the Department of Speech and Hearing Sciences, National University of Malaysia, Kuala Lumpur; and the Jahai community of Sungai Banun, Hulu Perak. I have benefited from interesting discussions with Alfred Daniels, Gérard Diffloth, Anetta Kopecka, Steve Levinson, Norizan Rajak and Andrew Turk, and I am grateful to Nick Enfield, Nicole Kruspe, Lye Tuck-Po, Asifa Majid, David Mark, Carolyn O’Meara, Gunter Senft, Andrew Turk, and two anonymous reviewers for their helpful comments on earlier drafts of this paper. The typeface has been adapted for formatting by Geoffrey Benjamin, Singapore, and I am thankful to him for supplying this version. Thanks also to Alex Dukers for preparing the figures. This work was carried out with the support of the Max Planck Society, a European Community Marie Curie Fellowship, and a Volkswagen Foundation DoBeS grant. The author is solely responsible for information communicated and the European Commission is not responsible for any views or results expressed.

\section{References}

Benjamin, G., 1976. An outline of Temiar grammar. In: Jenner, P.N., Thompson, L.C., Starosta, S. (Eds.), Austroasiatic Studies, Part I. The University Press of Hawaii, Honolulu, pp. 129-188.

Bohnemeyer, J., Burenhult, N., Enfield, N.J., Levinson, S.C., 2004. Landscape terms and place names elicitation guide. In: Majid, A. (Ed.), Field Manual, vol. 9. Max Planck Institute for Psycholinguistics, Nijmegen, pp. 7579.

Burenhult, N., 2005a. A Grammar of Jahai. Pacific Linguistics, Canberra.

Burenhult, N., 2005b. Landscape terms and toponyms in Jahai: A Field Report. Working Papers 51. Department of Linguistics, Lund, pp. 17-29.

Burenhult, N., 2006. Body part terms in Jahai. Language Sciences 28, 162-180.

Diffloth, G., 1976. Expressives in Semai. In: Jenner, P.N., Thompson, L.C., Starosta, S. (Eds.), Austroasiatic Studies, Part I. The University Press of Hawaii, Honolulu, pp. 249-264.

Hendricks, S., 2001. Bare-consonant reduplication without prosodic templates: expressive reduplication in Semai. Journal of East Asian Linguistics 10, 287-306.

Kruspe, N., 2004. A Grammar of Semelai. Cambridge University Press, Cambridge.

Levinson, S.C., 2003. Space in Language and Cognition: Explorations in Cognitive Diversity. Cambridge University Press, Cambridge.

Lye, T.-P., 1997. Knowledge, forest, and hunter-gatherer movement: the Batek of Pahang, Malaysia. Unpublished Ph.D. Dissertation, University of Michigan. 
Lye, T-P., 2004. Changing Pathways: Forest Degradation and the Batek of Pahang, Malaysia. Lexington Books, Lanham.

Mandelbrot, B.B., 1975. Les Objets Fractals: Forme, Hasard, et Dimension. Flammarion, Paris.

Mandelbrot, B.B., 1982. The Fractal Geometry of Nature. W.H. Freeman and Company, New York.

Matisoff, J.A., 1991. The mother of all morphemes: augmentatives and diminutives in areal and universal perspective. In: Ratliff, M., Schiller, E. (Eds.), Papers from The First Annual Meeting of The Southeast Asian Linguistics Society (SEALS). Arizona State University, Tempe, pp. 293-349.

Talmy, L., 2000. Toward a cognitive semantics. In: Typology and Process in Concept Structuring, vol. 2. The MIT Press, Cambridge MA.

van der Sluys, C.M.I., 1999. The Jahai of Northern Peninsular Malaysia. In: Lee, R.B., Daly, R. (Eds.), The Cambridge Encyclopaedia of Hunter-Gatherers. Cambridge University Press, Cambridge, pp. 307-311.

Wazir-Jahan, K., 1980. Introduction to the Ma' Betisek of Peninsular Malaysia. Federation Museums Journal 25, $119-158$. 